\title{
Cuidados de enfermagem a idosas com transtornos mentais em uma instituição de
}

\section{longa permanência}

\author{
Nursing care for the elderly women with mental disorders in a long-term institution \\ Cuidado de enfermería para las mujeres ancianas con trastornos mentales en una institución a
}

largo plazo

Recebido: 19/02/2021 | Revisado: 28/02/2021 | Aceito: 03/03/2021 | Publicado: 11/03/2021

Viviane Segabinazzi Saldanha

ORCID: https://orcid.org/0000-0001-5102-5636

Universidade Federal de Santa Maria, Brasil

E-mail: vivissaldanha@gmail.com

Margrid Beuter

ORCID: https://orcid.org/0000-0002-3179-9842

Universidade Federal de Santa Maria, Brasil E-mail: margridbeuter@gmail.com

Leila Mariza Hildebrandt

ORCID: https://orcid.org/0000-0003-0504-6166

Universidade Federal de Santa Maria, Brasil

E-mail: leilahildebrandt@yahoo.com.br

Marinês Tambara Leite

ORCID: https://orcid.org/0000-0003-3280-337X

Universidade Federal de Santa Maria, Brasil

E-mail: tambaraleite@yahoo.com.br

Rafael Beuter Nishijima

ORCID: https://orcid.org/0000-0002-5402-6121

Universidade Franciscana, Brasil

E-mail: rafaelnishijima@gmail.com

Carolina Backes

ORCID: https://orcid.org/0000-0002-2504-9105

Universidade Federal de Santa Maria, Brasil E-mail: karolbackes@hotmail.com

Francine Feltrin de Oliveira

ORCID: https://orcid.org/0000-0002-5105-7053

Universidade Federal de Santa Maria, Brasil

E-mail: francinefeltrin@uol.com.br

\begin{abstract}
Resumo
O estudo teve como objetivo conhecer a vivência dos profissionais de enfermagem de uma instituição de longa permanência para idosos, no cuidado de idosas com transtornos mentais. Trata-se de uma pesquisa qualitativa, descritiva realizada em uma instituição de longa permanência, na região sul do Brasil. A coleta de dados ocorreu de novembro de 2016 a janeiro de 2017 por meio de entrevista semiestruturada com 20 profissionais de enfermagem. Os dados foram analisados de acordo com a proposta operativa de Minayo. Os resultados mostraram a dificuldade dos profissionais ao lidar com idosas com transtornos mentais. O comportamento agressivo das idosas repercutiu no medo dos profissionais em relação às agressões. Condições institucionais - falta de pessoal e sobrecarga de trabalho - foram relatadas como fatores deletérios ao cuidado às idosas com transtornos mentais. Conclui-se que há desconhecimento dos profissionais sobre os transtornos mentais quanto a suas abrangências e complicações. Salienta-se a importância de outros profissionais para suprir as necessidades das idosas.
\end{abstract}

Palavras-chave: Idoso; Equipe de enfermagem; Instituição de longa permanência para idosos; Transtornos mentais.

\begin{abstract}
The study aimed to know the experience of nursing professionals of a long-term care institution for the elderly, in the care of elderly women with mental disorders. This is a qualitative and descriptive research conducted in a long-term institution from the southern Brazil. The data were collected between November 2016 and January 2017 through semi-structured interviews with 20 nursing professionals. The data were analyzed according to Minayo's operative proposal. The results showed the difficulty faced by professionals while dealing with the old women with mental disorders. The aggressive behavior presented by the elderly women had repercussions as fear in the professionals. Institutional conditions - lack of staff and work overload - were reported as deleterious factors in the care of the women with mental disorders. The professionals show ignorance about mental disorders and mostly on regards of
\end{abstract}


their scope and complications. The need for professionals from other fields, who are able to attend the the necessities of the elderly women, cannot be stressed enough.

Keywords: Aged; Nursing team; Homes for the aged; Mental disorders.

\section{Resumen}

El estudio tenía como objetivo conocer la experiencia de los profesionales de enfermería de una institución de cuidados a largo plazo para los ancianos, en el cuidado de mujeres de edad avanzada con trastornos mentales. Se trata de una investigación cualitativa y descriptiva realizada en una institución a largo plazo en el sur de Brasil. La recopilación de datos se produjo de noviembre de 2016 a enero de 2017 a través de entrevistas semiestructuradas con 20 profesionales de enfermería. Los datos fueron analizados de acuerdo con la propuesta operativa de Minayo. Los resultados mostraron la dificultad de los profesionales al tratar con las ancianas con trastornos mentales. El comportamiento agresivo de las ancianas tuvo repercusiones en el miedo de los profesionales en relación con las agresiones. Las condiciones institucionales - falta de personal y sobrecarga de trabajo- fueron reportadas como factores nocivos para el cuidado de las mujeres con trastornos mentales. Se concluye que hay ignorancia de los profesionales sobre los trastornos mentales con respecto a su alcance y complicaciones. Se hace hincapié en la importancia de otros profesionales para satisfacer las necesidades de las ancianas.

Palabras clave: Anciano; Grupo de enfermería; Hogares para ancianos; Trastornos mentales.

\section{Introdução}

Os transtornos mentais geram modificações no cotidiano e produzem alterações de natureza orgânica e psíquica nas pessoas, incluindo os idosos, necessitando de cuidados amplos e específicos. Os transtornos mentais, especialmente os quadros depressivos, representam uma das principais causas de incapacidades em nível mundial, seguidos pelos transtornos bipolares, esquizofrênicos e outros quadros psicóticos, demências, deficiência intelectual e transtornos relacionados ao desenvolvimento (Organização Pan-Americana de Saúde, 2021).

Considerando esse contexto, ressalta-se que a população idosa apresenta diferentes condições de adoecimento mental, com ênfase aos quadros depressivos e demenciais. Um estudo com 360 idosos atendidos em um Centro de Referência para Assistência à Saúde do Idoso identificou a prevalência de sintomas depressivos em 37,2\% dessa população (Silva, Aguiar, Vieira, Costa, \& Carneiro, 2019) e outra pesquisa com 260 idosos cadastrados em Unidades de Saúde da Família constatou que 25\% deles possuíam sintomatologia depressiva (Abrantes et al., 2019). Já, uma investigação desenvolvida em uma instituição de longa permanência para idosos verificou que 54,8\% dos 42 residentes possuíam sintomas depressivos (Guimarães et al., 2019). Ainda, pesquisa em um ambulatório de memória de uma universidade catarinense, a partir da análise de prontuários de idosos acompanhados nesse espaço, identificou prevalência de 16,72\% deles com demência e 42,50\% com depressão (Santos, Bessa, \& Xavier, 2020).

O cuidado em saúde mental necessita ser considerado diante do envelhecimento populacional. O aumento do número de pessoas idosas com transtornos mentais direciona para reflexões e mudanças de atitude sobre o cuidado nessa área. Salientase que o transtorno mental se constitui em uma síndrome caracterizada pela alteração dos processos cognitivos, que se traduz em perturbações clínicas significativas em nível emocional e de comportamento, refletindo na compreensão da realidade e na adaptação às condições da vida (American Psychiatric Association [APA], 2014).

O processo de envelhecimento produz uma série de modificações na pessoa, envolvendo aspectos físicos, emocionais e cognitivos. Nesse cenário, podem aparecer as demências que se caracterizam pelo déficit cognitivo, alterações de memória, discurso pobre e perturbações comportamentais (Sadock, Sadock, \& Ruiz, 2017) que comprometem o viver da pessoa idosa. Assim sendo, a atenção à saúde do idoso representa um desafio para os serviços que atendem essa população, em função das suas demandas que comumente são complexas e abrangentes, com o envolvimento do idoso, da família, da sociedade e dos profissionais da saúde (Marin, Maftum, \& Lacerda, 2018).

As Instituições de Longa Permanência para Idosos [ILPI] têm o papel de prestar atenção integral aos seus moradores. Nelas residem idosos com diferentes condições sociais, culturais e de saúde, incluindo aqueles com transtornos mentais. Desse 
modo, tais instituições enfrentam o desafio de fornecer cuidado adequado às demandas dessa população. Dentre os profissionais responsáveis pelo cuidado da pessoa idosa em uma ILPI estão os da equipe de enfermagem: considerados indispensáveis para desenvolver atividades diretas ao processo de cuidar (Medeiros, Oliveira, Lima, \& Nóbrega, 2015).

São relevantes estudos que buscam entender como agir frente aos idosos com transtornos mentais, uma vez que há fragilidades na formação de profissionais em relação às particularidades do cuidado gerontológico (Damaceno, Chirelli, \& Lazarini, 2019) e de saúde mental (Oliveira et al., 2020; Pereira, Duarte, \& Eslabão, 2019), especialmente em ILPI.

Neste contexto, os profissionais precisam ter uma visão capaz de discernir alterações nas condições física, psíquica e cognitiva dos idosos. Assim, considera-se importante conhecer como profissionais de enfermagem de ILPI vivenciam o cuidado a idosos com transtornos mentais, pois os achados permitirão refletir sobre as práticas de cuidado aos idosos institucionalizados.

Diante do exposto, tem-se a questão de pesquisa: como profissionais de enfermagem de uma ILPI vivenciam o cuidado a idosas com transtornos mentais? E como objetivo do estudo, conhecer as vivências dos profissionais de enfermagem no cuidado a idosas com transtornos mentais em uma ILPI.

\section{Metodologia}

Trata-se de um estudo qualitativo e descritivo que busca conhecer a vivência dos profissionais de enfermagem de uma ILPI, no cuidado de idosas com transtornos mentais. A pesquisa qualitativa é empregada no estudo das relações, das crenças e das percepções possibilitando a interpretação de vivências e sentimentos (Minayo, 2014). Enquanto a pesquisa descritiva propõe a descrição de fatos, fenômenos de determinada população (Gil, 2017).

A pesquisa foi realizada em uma ILPI filantrópica, na região sul do Brasil, que atendia em torno de 190 idosas no período da coleta de dados. A escolha deste cenário deu-se pelo fato da ILPI possuir uma ala psiquiátrica de acesso restrito e de circulação controlada. Esse setor atende idosas com transtornos mentais que possuem algum risco de fuga da instituição e de lesão corporal a si mesma ou outras moradoras. Além disso, a ILPI possui idosas com algum tipo de transtorno mental em outras alas sem restrição de mobilidade. Assim, percebe-se que o transtorno mental não é um critério suficiente para o ingresso na ala psiquiátrica, sendo os riscos de fuga e agressão os motivos determinantes para o isolamento.

A coleta de dados ocorreu no período de novembro de 2016 a janeiro de 2017. Nessa ocasião a equipe de enfermagem da instituição era composta por oito enfermeiros e 31 técnicos de enfermagem. Fizeram parte da pesquisa 20 profissionais entre enfermeiros e técnicos. Como critérios de inclusão, participaram profissionais da equipe de enfermagem da ILPI com vínculo empregatício há pelo menos três meses na instituição. Foram excluídos os profissionais afastados do trabalho no período de coleta de dados por motivos de saúde, férias ou licença maternidade.

A entrevista foi norteada por um roteiro de pesquisa previamente formulado, composto pelas seguintes perguntas: o que você entende por problemas mentais/transtornos mentais? Como é para você cuidar das idosas com problemas mentais/transtornos mentais? Como você lida (atua, reage) em situação de crise (descontroles/surtos) das idosas com problemas mentais/transtornos mentais? Quais as principais dificuldades que você enfrenta em cuidar de idosas com problemas mentais/transtornos mentais? As entrevistas foram realizadas na própria instituição, durante o intervalo do horário de trabalho dos participantes, gravadas em áudio e transcritas.

Os dados foram analisados com base na proposta operativa de Minayo (2014), caracterizada por dois níveis de interpretação. No primeiro nível faz-se um mapeamento das determinações fundamentais da pesquisa e ocorre na fase exploratória da investigação. O segundo nível denomina-se interpretativo, representa o encontro com os fatos empíricos, em que é necessário procurar, nos relatos dos informantes, o sentido, a lógica interna, as projeções e as interpretações. Essa fase apresenta duas etapas: a ordenação e a classificação dos dados. 
A pesquisa foi aprovada pelo Comitê de Ética e Pesquisa da instituição, sob o certificado de Apresentação para Apreciação Ética CAAE No 59590216.1.0000.5346. A fim de preservar a identidade dos participantes do estudo, os discursos foram identificados com as siglas ENF (Enfermeiro) e TEC (Técnico de enfermagem), seguidos de números arábicos de forma aleatória.

\section{Resultados}

Participaram do estudo cinco enfermeiros e 15 técnicos de enfermagem. Destes, 18 eram do sexo feminino e dois do sexo masculino. A idade dos participantes variou de 26 a 52 anos, em que 13 deles estavam na faixa etária de 30 a 49 anos.

O tempo de serviço na instituição variou de cinco meses a oito anos. Do total de profissionais, três estavam na instituição a menos de um ano. Verificou-se que seis profissionais possuíam outro vínculo empregatício, tal como professor ou cuidador particular de idosos. Nenhum profissional apresentava curso de especialização na área da gerontologia, entretanto, dois relataram ter curso na área de saúde mental.

A partir dos dados obtidos nas entrevistas, elaboraram-se três categorias temáticas: "Transtorno mental na percepção dos profissionais de enfermagem"; "O cuidado dos profissionais de enfermagem em relação às manifestações decorrentes do transtorno mental"; e "Condições institucionais que interferem no cuidado de idosas com transtornos mentais".

\subsection{Transtorno mental na percepção dos profissionais de enfermagem}

Os trabalhadores compreenderam que o transtorno mental está associado a acontecimentos pregressos da vida, relacionado aos traumas ou doenças vivenciadas no passado da pessoa idosa.

Eu acho que vem de coisas passadas, de traumas, sabe? E isso fica na cabeça delas. Cada uma, eu acho que passou por alguma dificuldade, por algum trauma antes de vir para cá e foi só se agravando. Daí bagunçou tudo de vez na cabecinha delas (TEC 07).

Entre as diferentes concepções sobre os transtornos mentais, os participantes os caracterizaram como fenômenos relacionados aos aspectos biológicos, o que incorre nas atitudes fora dos padrões éticos e sociais.

Não é igual a alguém que tem um discernimento, elas não têm. Não entendem, não raciocinam direito, não têm aquela ideia. Ela (idosa) não faz por gosto isso, daí ela não quer esquecer as coisas, é um probleminha que deu, cerebral e vamos trabalhar isso aí... é uma doença (TEC 03).

Acho que é um problema neurológico, a pessoa não sabe o que está fazendo. Eu acho que elas não sabem o que fazem (TEC 09).

Seria não associar o que está acontecendo, não saber o que está acontecendo ao redor. Com o transtorno mental ela para no tempo (TEC 15).

O transtorno mental, no caso dessas vós, acho que seria a degeneração fisiológica, biológica do próprio cérebro. E elas ficam sem a capacidade de dar continuidade para o pensamento e essas coisas assim (TEC 13). 


\subsection{O cuidado dos profissionais de enfermagem em relação às manifestações decorrentes do transtorno mental}

Condutas permeadas pela paciência são adotadas pela equipe de enfermagem no cuidado às idosas com transtorno mental institucionalizadas no intuito de prevenir a agudização dos sintomas. Associado a isso, os profissionais ressaltaram a importância de conhecer as características de personalidade das idosas e suas preferências, para que esses elementos sejam considerados no momento da intervenção nas situações de crise.

Tu tens que ter calma e visão da situação e saber qual é a personalidade dela. Que ela não é só aquele surto, ela tem também a personalidade dela quando ela está boa, então tem que saber do que ela gosta (TEC 03).

Os profissionais aprenderam a identificar sinais, como alteração do comportamento, que caracterizam a agudização dos sintomas psiquiátricos e uma possível antecipação da crise.

Eu conheço elas já assim pelo olhar. Ela me dá um sinal que vai surtar. [...] elas desenvolvem uma agressividade na fala, no olhar. Principalmente no olhar. Eu vejo muito o olhar. Porque elas têm um olhar... geralmente é um perdido, um olhar fixo, mas quando elas ficam com aquele olhar que tu percebes uma raiva ou que você vê que ela está, por mínimas coisas, aquilo está incomodando... (ENF 03).

A conversa, aliada a outros recursos, foi considerada uma das formas de intervenção utilizada pelos profissionais de enfermagem junto às idosas com transtorno mental, no momento da agudização dos sintomas psíquicos.

Porque às vezes só de tu caminhar, conversar com elas, às vezes elas se acalmam, [...] na maioria das vezes eu tento sentar e calmamente, de longe, chegando de mansinho para conversar, porque muitas vezes tu chega assim: "Fulana, o que que aconteceu?" Ou se chegar muito eufórica, isso deixa elas mais nervosas (ENF 02).

Se eu acho que dá para controlar, eu tento conversar com elas. Pego um pouco de água, tento acalmar e conversar com elas, se eu acho que eu consigo (TEC 09).

Quando a abordagem por meio da conversa é insuficiente, a contenção, social ou mecânica, é outro recurso utilizado como forma de tentar controlar os sintomas do transtorno mental apresentado pelas idosas.

Ah... a gente tenta acalmar, leva para o corredor, senta ela no quarto, ou oferece alguma coisinha para comer... e ela sempre aos berros. (...) E ali na ala $X$ a gente às vezes contêm, porque às vezes elas caem se quebram ou tiram a sonda. (...) coloca assim, uma compressinha (mostra os punhos) e ata com lençol na cama. Daí elas não têm como se machucar e ficam mais quietinhas (TEC 03).

A utilização da medicação constitui-se em outra estratégia, utilizada por parte da enfermagem, para controlar ou minimizar os sintomas agudos manifestados pelas idosas com transtornos mentais.

Quando elas entram em surto mesmo, que não tem como acalmar elas, a gente chama as enfermeiras, né. Que geralmente tem que medicar, porque a gente não consegue acalmar elas (TEC 10). 
Os profissionais de enfermagem relataram a importância de criar atividades para a idosa com transtorno mental, que está com os sintomas agudizados, para evitar crises, por meio da distração.

Eu procuro acalmar elas, acalmar... achar alguma coisa que elas se ocupem - entendeu? Acalmar, respirar fundo, eu procuro uma atividade para entreter ela, a mente dela, para desenvolver, outra para passar a crise (TEC 06).

Eu converso. Daí eu digo assim: Vamos sair? Se tu tomar teu remédio, se vestir, tal roupa, eu saio. Vamos passear, vamos se arrumar pra nós passear, vou te levar em casa, depois vamos sair e passear no pátio (TEC 12).

Diante de situações quando é evidenciada a presença de sintomas agudos em idosas com transtorno mental, a procura e o apoio fornecido por outros profissionais foram considerados estratégias de intervenção da equipe.

Naquele dia tinha o médico aqui, mas quando não tem, a gente liga pra psiquiatra e ela nos passa a conduta de acordo com o 'andar da carruagem'. [...] às vezes a gente acaba tendo que fazer várias 'pontes' pra poder conseguir fazer um procedimento que não seja tão agressivo (ENF 03).

A gente comunica o enfermeiro, a gente tenta amenizar a situação da melhor forma possível e depois tem que encaminhar pro médico pra ver se precisa mudar o tratamento (TEC 07).

Se tivesse um profissional de educação especial, que é onde se trabalha com esse tipo de doença e passasse um pouco de orientação pra poder ajudar, seria melhor (TEC 08).

\subsection{Condições institucionais que interferem no cuidado de idosas com transtornos mentais}

Os participantes do estudo consideraram que o número de profissionais é insuficiente para atender as demandas de todas as idosas - gerando sobrecarga no trabalho diário.

Na verdade, se a gente fosse cuidar realmente como a gente tem que cuidar delas, seria bem diferente. Mas é que como somos poucos, daí fica difícil de suprir todas as necessidades delas. Porque a gente não tem tempo de sentar com elas e conversar (TEC 12).

Os participantes abordaram a importância da assistência multiprofissional para as atividades de socialização das idosas da ILPI, o que carece na instituição lócus da pesquisa.

Ter um psicólogo com maior carga horária, ter mais atividades terapêuticas pra elas, ter outras equipes... terapia ocupacional, outros profissionais que pudessem mantê-las ocupadas por mais tempo (ENF 05).

A necessidade de formação dos profissionais para o cuidado com o idoso foi outro tema abordado pela equipe de enfermagem.

Eu queria entender elas melhor. Eu queria, como é que vou te dizer - três anos quase - de formada, às vezes eu tenho vontade assim de pesquisar, de fazer algum curso a mais (TEC 01). 
E um maior treinamento pra gente, porque é como eu te disse, depois que eu comecei a trabalhar aqui no lar, eu não lembro da metade do meu curso. Eu não lembro de mais nada, porque o que basicamente a gente faz é trocar fralda, é dar banho, é dar medicação que já vem pronta e dar comida, mais nada (TEC 13).

\section{Discussão}

As dificuldades apresentadas pelos profissionais para atribuir um significado ao transtorno mental são justificadas como consequência de um acontecimento traumático vivido pela pessoa durante a trajetória de vida - como uma situação fora do controle do sujeito. As enfermidades mentais possuem um conjunto de causas que, articuladas entre si, podem desencadear o processo de adoecimento mental, relacionadas a fatores genéticos, orgânicos e psicossociais vivenciados no transcorrer da vida (Damaceno, Chirelli, \& Lazarini, 2019). Além disso, o Manual Diagnóstico e Estatístico de Transtornos Mentais aponta as questões culturais como uma das causas de transtornos mentais: definidas em relação às normas e valores culturais, sociais e familiares (APA, 2014). Estudo com idosos residentes em uma ILPI baiana identificou fatores associados a sintomas depressivos vivenciados por essa população no presente, como estar aposentado, possuir incontinência urinária, ter autopercepção negativa de sua saúde e apresentar qualidade ruim de sono, porém não apontou fatos vividos na sua vida pregressa (Guimarães et al., 2019).

Os participantes do estudo, ao atribuírem o adoecimento mental como uma alteração orgânica capaz de comprometer a cognição das idosas, entendem que elas não têm controle sobre suas ações e são isentas da capacidade de compreender situações vividas no cotidiano. Pessoas com transtorno mental foram e ainda são vistas pela sociedade como incapazes, perigosas e com dificuldades para o convívio social. Pesquisa com pessoas acometidas por enfermidade mental apontou presença de estigma e preconceito advindo de diversos contextos como: familiar, social, escolar, laboral, religioso e do próprio espaço de tratamento - em função do diagnóstico que exacerbou o sofrimento psíquico (Silva \& Marcolan, 2018).

Salienta-se que, em razão desse entendimento, ainda, há muitas instituições que utilizam espaços fechados para o acompanhamento de pessoas que possuem algum distúrbio mental. Embora isso aconteça, nos dias de hoje, defende-se que não há razão para restringir a liberdade de uma pessoa com transtorno mental, considerando que alguns transtornos podem afetar apenas habilidades de comunicação, de socialização ou de cuidado pessoal, sem comprometer a memória, a atenção ou o raciocínio (Basile, 2015).

É possível observar nas falas dos profissionais de enfermagem um conhecimento teórico insuficiente, visto que a significação acerca dos transtornos mentais possui estereótipos sobre a loucura, característicos do saber manicomial. Em algumas falas foram reconhecidos sentimentos e percepções estigmatizantes, o que prejudica as ações de assistência oferecida às idosas. E os profissionais reconhecem, em algum aspecto, essas barreiras provenientes de suas dificuldades que interferem na oferta do cuidado adequado durante suas jornadas de trabalho.

Os idosos com transtornos mentais requerem cuidados condizentes com sua condição e, para tanto, é preciso qualificar os profissionais de saúde no sentido de que possam ter habilidades para reconhecer as necessidades dessa população e reduzir o estigma e a exclusão social. Também, construir meios de inserir concepções relativas ao atual modelo de atenção à saúde mental, em que as pessoas possam ser assistidas nos seus locais de convívio e ter direito de ir e vir, sem restrições de liberdade.

A agudização dos sintomas psiquiátricos caracteriza-se pela alteração de pensamentos, emoções e condutas e pode culminar em uma urgência ou emergência psiquiátrica. Tal situação requer intervenções no sentido de evitar prejuízos físicos e emocionais e minimizar possíveis riscos à vida da pessoa ou a de outros a sua volta (Quevedo, 2020). 
Assim, conhecer aspectos da personalidade e da subjetividade da idosa com transtorno mental foram considerados importantes para intervir de maneira efetiva na situação de agudização dos sintomas. Tais conhecimentos permitem conduzir as idosas às atividades de sua preferência a fim de desviar sua atenção - evitando a crise.

$\mathrm{Na}$ convivência diária, os profissionais de enfermagem percebem algumas mudanças sugestivas à agudização dos sintomas psiquiátricos nas idosas. A principal mudança é a alteração de comportamento da idosa: pela fala, jeito de olhar e recusa para realizar as atividades de rotina. A equipe de enfermagem vale-se do diálogo a fim de atenuar ou dirimir a agudização dos sintomas psíquicos. Compreendem que, durante a conversa, se deve demonstrar afeto e calma para evitar uma reação negativa da idosa à abordagem.

A intervenção exige habilidades interpessoais que envolvem o diálogo, a escuta, o acolhimento e o vínculo profissional junto a pacientes com transtornos mentais como no caso das idosas com essa enfermidade. Isto favorece a promoção da saúde mental e pode colaborar na superação das crises psiquiátricas (Oliveira, Siqueira Junior, \& Furegato, 2019). Por esse motivo, uma boa relação entre os profissionais de enfermagem e as idosas com transtornos mentais é importante durante o processo do cuidado e da manutenção da estabilidade psicoemocional das idosas.

Há duas formas de contenção efetuadas na instituição. Uma forma de contenção aplicada é a social, para manter a idosa com transtorno mental afastada do grupo por apresentar risco de agressão, tanto para as outras idosas, quanto para a equipe. Enquanto a contenção mecânica é utilizada como forma de proteção às idosas com comprometimento cognitivo mais acentuado. Os profissionais valem-se desta técnica por entender que são inibidos eventos causados por quedas ou retirada dos dispositivos de alimentação.

A contenção acompanha a história da psiquiatria, remete-se às antigas instituições manicomiais, caracterizadas pela exclusão social, isolamento e coerção, reconhecidas como violações dos direitos humanos e sociais da pessoa com transtorno mental. Nos dias de hoje, mesmo com o Movimento da Reforma Psiquiátrica, as restrições físicas ou mecânicas são ainda frequentes. Todavia, a contenção mecânica deve ser utilizada quando outros recursos se tornarem insuficientes, a exemplo da abordagem verbal, com a finalidade de proteger o paciente e a equipe, evitar lesões, traumas e quedas. Ela deve ser um recurso terapêutico e não repressivo, além de ser executada de forma respeitosa, com vistas a garantir a segurança do paciente (DelBem et al., 2017; Maximo, Santos, Santos, \& Silva, 2019). Em situações em que a comunicação terapêutica é considerada ineficiente, se aposta na imposição de limites por meio da restrição de espaço e/ou a contenção física quando a pessoa com distúrbios mentais oferece risco para si e a terceiros - como à equipe que a atende (Silva \& Marcolan, 2018).

Participante relata que, em casos específicos, uma vez que a escuta terapêutica ou o isolamento social não foram efetivos, é necessário o uso de medicações para minimizar os sintomas psíquicos apresentados pela idosa. A administração de medicações psicotrópicas deve ser considerada uma das últimas alternativas com o objetivo de tranquilizar o paciente reduzindo o risco de agressão para si ou a outros envolvidos - para possibilitar a continuidade da abordagem terapêutica (DelBem et al., 2017).

Os profissionais da enfermagem buscam desviar o aparente foco da situação desencadeadora da agudização dos sintomas psiquiátricos. Assim, enquanto a idosa com transtorno mental estiver envolvida com atividades que lhe proporcione prazer ou entretenimento, como um passeio, poderá ser evitado o agravamento dos seus sintomas. A realização de atividades lúdicas e de socialização colaboram para diminuir ansiedade das idosas. Estudo com idosos de uma ILPI identificou que a prática de atividades físicas e lúdicas colaborou para a integração entre os residentes, promoveu mudanças positivas com maior interação e comunicação, fortaleceu vínculos e diminuiu o isolamento. Ainda, esse mesmo estudo pontuou que tais atividades estimularam memória remota e recente, possibilitaram a expressão de emoções e desejos e melhoraram autoestima dos idosos (Guimarães, Dutra, Silva, Vieira-Silva, \& Maia, 2016). Embora esta pesquisa não se reporte especificamente a idosos com 
transtornos mentais, compreende-se que atividades dessa natureza também possam ser benéficas para estas pessoas, com resultados positivos na minimização dos sintomas psiquiátricos.

Os relatos dos participantes demonstram que é necessária a intervenção de outros profissionais para oferecer o cuidado apropriado às idosas com transtornos mentais. Tal intervenção tem a intenção de qualificar o atendimento fornecido pelos profissionais de enfermagem, para que possam agir de maneira adequada - evitando provocar complicações e sintomas no atendimento às idosas - durante o enfrentamento de situações em que os sintomas psiquiátricos estejam presentes ou possam ser suscitados.

$\mathrm{Na}$ exacerbação dos sintomas psiquiátricos, o indivíduo manifesta suas angústias e sofrimentos, impassível às constrições sociais e normas de conduta esperadas, por vezes, saindo da realidade comum e perdendo-se na própria realidade interna. Portanto, para o atendimento da crise, é ideal que exista uma equipe multidisciplinar qualificada que encontre formas de prestar cuidado adequado para acolher o sofrimento e sentimentos do indivíduo (Ministério da Saúde, 2003).

Denota-se que os participantes somente reconhecem como sintomas psiquiátricos quando há agudização: em momentos de agitação, hiperatividade e agressividade. Percebeu-se o não reconhecimento por parte dos profissionais de alterações comportamentais de caráter apático - como sinais de exacerbação dos sintomas psiquiátricos -, sendo que elas estão inclusas entre os sinais de agudização dos sintomas de alguns quadros psiquiátricos (Sadock, Sadock \& Ruiz, 2017). Provavelmente isso se deva ao pouco conhecimento relativo à área da saúde mental por parte dos profissionais de enfermagem vinculados à ILPI.

Embora em cenário diferente, estudo com enfermeiros vinculados à Estratégia de Saúde da Família e Centro de Atenção Psicossocial de um município mineiro, que assistiam pessoas com transtornos mentais, identificou carência de conhecimentos acerca da área da saúde mental, insegurança e medo que repercutiam negativamente na atenção às pessoas com enfermidades mentais (Almeida et al., 2020).

As condições institucionais são elementos que interferem direta ou indiretamente no cuidado às idosas com transtornos mentais. Esses elementos são considerados fundamentais para a melhoria da assistência, não só das idosas com transtornos mentais, como para as demais moradoras da instituição.

$\mathrm{O}$ trabalho de enfermagem prestado na ILPI foi considerado extenuante pela sobrecarga - devido ao elevado número de idosas a serem atendidas. O relato apontou que, se houvesse maior número de funcionários, a equipe poderia permanecer mais tempo com elas e oferecer uma assistência mais qualificada. Tal problemática é provocada pelo ritmo acelerado da rotina do trabalho frente às demandas do cuidado na ILPI e pelo número insuficiente de profissionais (Mariano, Baldissera, Martins, \& Carreira, 2015).

Investigação sobre o dimensionamento de pessoal de enfermagem em ILPI, desenvolvida no Rio de Janeiro, indica falta de enfermeiros e técnicos de enfermagem: estando em desacordo com o recomendado pela legislação vigente. A investigação salienta que há necessidade de as ILPIs realizarem cálculo de dimensionamento de pessoal específico para instituições dessa natureza (Paula, Rodrigues, \& Santana, 2018). Destaca-se que o reduzido número de profissionais provoca sobrecargas e pode comprometer a assistência das idosas com transtornos mentais, em função de que as demandas dessas pessoas têm especificidades e exigem habilidades interpessoais como paciência, diálogo, escuta, acolhimento, vínculo por parte da equipe, o que pode contribuir para a superação da crise psíquica (Oliveira, Siqueira Junior \& Furegato, 2019).

Foi reconhecida a importância do trabalho de outros profissionais na assistência às idosas - levando em consideração a jornada sobrecarregada da equipe de enfermagem pelo número reduzido de integrantes. Destaca-se a relevância da atuação da equipe multiprofissional para a melhora do comportamento e do sedentarismo encontrados no dia a dia das idosas com transtorno mental da ILPI. O trabalho em equipe produz resultados positivos na assistência a idosos com transtornos mentais, como foi constatado em estudo de revisão bibliográfica acerca de ações multidisciplinares/interdisciplinares na atenção ao 
idoso com Doença de Alzheimer, cujas evidências apontaram eficácia dos cuidados da equipe multidisciplinar no controle do declínio cognitivo dos idosos e melhora da sua qualidade de vida e de seus familiares (Bertazone et al., 2016).

Alguns participantes do estudo relataram a tenuidade e, às vezes insuficiência, dos conhecimentos adquiridos durante os anos de formação profissional. Assim, não é surpreendente que haja dificuldades em atender a população idosa. Nessa perspectiva, estudo reitera a necessidade de fortalecer discussões entre instituições de ensino formadoras e serviços de saúde na perspectiva de construir, de forma coletiva, projetos pedagógicos que norteiam a formação de profissionais de saúde, cujas discussões sobre o envelhecimento e trabalho interprofissional, balizados pelos princípios do Sistema Único de Saúde, possam perpassar os referidos cursos (Lima, Vilar, Castro, \& Lima, 2018).

\section{Conclusão}

O presente estudo possibilitou conhecer a vivência dos profissionais de enfermagem de uma ILPI no cuidado a idosas com transtornos mentais, evidenciando a complexidade que permeia esse fazer, uma vez que os participantes relatam que há situações em que a equipe não se sente preparada para atuar com idosas acometidas por transtornos mentais.

Os relatos apontaram que os profissionais possuem conhecimento teórico restrito acerca do transtorno mental. Outrossim, observou-se em relatos de alguns profissionais percepções e sentimentos estigmatizantes sobre o transtorno mental, baseadas no saber manicomial, o que pode repercutir em atitudes inadequadas à assistência dessas idosas.

Os profissionais de enfermagem relataram suas condutas frente à agudização de sintomas que acometem as idosas com transtornos mentais. Conhecer o comportamento das idosas e suas preferências foram fatores que potencializaram ou permitiram atender a idosa e até interromper a agudização. Para tanto, os profissionais valem-se de uma identificação dos sinais característicos da exacerbação dos sintomas psiquiátricos, sinais que aprendem a identificar pela prática profissional na ILPI. Para interromper a agudização, os profissionais utilizam, primeiramente, o diálogo, e se ocorrer insucesso, procedem para empregar a contenção (social ou mecânica) - sendo que profissionais da equipe multiprofissional são acionados nesse processo.

As condições institucionais, como a falta de pessoal e a sobrecarga do trabalho de enfermagem, foram relatadas como fatores que dificultam o cuidado mais atento e dedicado às idosas com transtornos mentais na ILPI. E os profissionais de enfermagem expressaram que um maior número de funcionários possibilitaria a oferta de assistência mais qualificada.

Ainda, foi identificada pelos profissionais a necessidade de assistência multiprofissional, cuja atuação poderia contribuir com a melhora do comportamento e redução do sedentarismo no dia a dia das idosas com transtorno mental.

Também foi apontada a defasagem e/ou insuficiência dos conhecimentos adquiridos na formação profissional. E a falta de acesso a cursos de atualização ou aperfeiçoamento na área da psiquiatria/ gerontologia foram relatados como fatores que dificultam o cuidado às idosas com transtornos mentais.

Sobressaiu a necessidade de implantar programas de capacitação e sensibilização dos profissionais quanto aos cuidados das idosas com transtornos mentais. Fornecer uma capacitação adequada constitui um empoderamento do profissional, possibilitando intervir nos problemas de saúde da população, seja ela idosa ou não, de posse do saber e da prática específicos para atender à complexidade da demanda.

Como contribuição deste estudo, conhecendo as dificuldades que interferem no trabalho dos profissionais de enfermagem no cuidado às idosas com transtornos mentais na ILPI, pode-se elaborar estratégias ou desenvolver medidas para melhorar a prática da enfermagem - além de propender à reflexão. Entretanto, a realização da pesquisa em apenas uma instituição constitui uma limitação ao escopo dos dados obtidos.

A partir dos resultados e frente à carência de estudos brasileiros, identifica-se a importância de novos estudos aprofundando a temática sobre o cuidado de enfermagem a idosos com transtornos mentais residentes em ILPI. 


\section{Referências}

Abrantes, G. G., Souza, G. G., Cunha, N. M., Rocha, H. N. B., Silva, A. O., \& Vasconcelos, S. C. (2019). Sintomas depressivos em idosos na atenção básica à saúde. Revista Brasileira de Geriatria e Gerontologia, 22(4), e190023. https://doi.org/10.1590/1981-22562019022.190023

Almeida, D. R., Soares, J. N. C., Dias, M. C., Rocha, F. C., Andrade, G. R. N., \& Andrade, D. L. B. (2020). O cuidado aos portadores de sofrimento mental na atenção primária: uma prática interdisciplinar e multiprofissional. Revista de Pesquisa: Cuidado é Fundamental Online, 12, 454-459. http://dx.doi.org/10.9789/2175-5361.rpcfo.v12.8388

American Psychiatric Association. (2014). DSM 5. Artmed.

Basile, F. (2015). Capacidade Civil e o Estatuto da Pessoa com Deficiência. Brasília: Núcleo de Estudos e Pesquisas/CONLEG/Senado. https://www12.senado.leg.br/publicacoes/estudos-legislativos/tipos-de-estudos/boletins-legislativos/bol40

Bertazone, T. M. A., Ducatti, M., Camargo, H. P. M., Batista, J. F. M., Kusumota, L., \& Marques, S. (2016). Ações multidisciplinares/interdisciplinares no cuidado ao idoso com Doença de Alzheimer. Revista Rene, 17(1), 144-153. http://periodicos.ufc.br/rene/article/view/2633

Damaceno, D. G., Chirelli, M. Q., \& Lazarini, C. A. (2019). The practice of care in long-term care facilities for the elderly: a challenge for the training of professionals. Revista Brasileira de Geriatria e Gerontologia, 22(1), e180197. https://doi.org/10.1590/1981-22562019022.180197

Del-Bem, C. M., Sponholz-Junior, A., Mantovani, C., Faleiros, M. C. M., Oliveira, G. E. C., Guapo, V. G., \& Marques, J. M. A. (2017). Emergências psiquiátricas: manejo de agitação psicomotora e avaliação de risco suicida. Medicina, 50(supl. 1), 98-112. https://doi.org/10.11606/issn.21767262.v50isupl1.p98-112

Gil, A. C. (2017). Como elaborar projetos de pesquisa. (6a ed.). Atlas.

Guimarães, A. C., Dutra, N. S., Silva, G. L. S., Vieira-Silva, M., \& Maia, B. D. C. (2016). Atividades grupais com idosos institucionalizados: exercícios físicos funcionais e lúdicos em ação transdisciplinar. Pesquisas e Práticas Psicossociais, 11(2), 443-452. http://pepsic.bvsalud.org/pdf/ppp/v11n2/13.pdf

Guimarães, L. A., Brito, T. A., Pithon, K. R., Jesus, C. S., Souto, C. S., Souza, S. J. N., \& Santos, T. S. (2019). Sintomas depressivos e fatores associados em idosos residentes em instituição de longa permanência. Ciência \& Saúde Coletiva, 24(9), 3275-3282. https://doi.org/10.1590/1413-81232018249.30942017

Lima, R. R. T., Vilar, R. L. A., Castro, J. L., \& Lima, K. C. (2018). A educação interprofissional e a temática sobre o envelhecimento: uma análise de projetos pedagógicos na área da Saúde. Interface - Comunicação, Saúde, Educação, 22(supl. 2), 1661-1673. https://doi.org/10.1590/1807-57622017.0466

Mariano, P. P., Baldissera, V. D. A., Martins, J. T., \& Carreira, L. (2015). Nursing work organization in long-stay institutions for the elderly: relationship to pleasure and suffering at work. Texto \& Contexto - Enfermagem, 24(3), 756-765. http://dx.doi.org/10.1590/0104-070720150-1150014

Marin, M. J. S., Maftum, M. A., \& Lacerda, M. R. (2018). Idosos com transtornos mentais: vivenciando o uso de psicofármacos. Revista Brasileira de Enfermagem, 71(supl. 2), 835-843. https://doi.org/10.1590/0034-7167-2016-0159

Maximo, P. A., Santos, T. S., Santos, G. S., \& Silva, M. A. X. M. (2019). A importância da contenção mecânica e a avaliação permanente da equipe de enfermagem. Brazilian Journal of Health Review, 2(2), 1172-1212. http://www.brjd.com.br/index.php/BJHR/article/view/1324

Medeiros, F. A. L., Oliveira, J. M. M., Lima, R. J., \& Nóbrega, M. M. L. (2015). O cuidar de pessoas idosas institucionalizadas na percepção da equipe de enfermagem. Revista Gaúcha de Enfermagem, 36(1), 56-61. https://seer.ufrgs.br/RevistaGauchadeEnfermagem/article/view/45636

Minayo, M. C. S. (2014). O desafio do conhecimento: pesquisa qualitativa em saúde (14a ed.). Hucitec.

Ministério da Saúde (BR). (2003). A política do Ministério da Saúde para a atenção integral a usuários de álcool e outras drogas. Brasília, Ministério da Saúde. http://bvsms.saude.gov.br/bvs/publicacoes/politica_atencao_alcool_drogas.pdf

Oliveira, L. C., Menezes, H. F., Oliveira, R. L., Lima, D. M., Fernandes, S. F., \& Silva, R. A. R. (2020). Atendimento móvel às urgências e emergências psiquiátricas: percepção de trabalhadores de enfermagem. Revista Brasileira de Enfermagem, 73(1), e20180214. https://doi.org/10.1590/0034-7167-2018-0214

Oliveira, R. M., Siqueira Junior, A. C., \& Furegato, A. R. F. (2019). Cuidados de enfermagem ao paciente psiquiátrico e ao paciente de outras especialidades: percepção da enfermagem. Revista Mineira de Enfermagem, 23, e-1198. http://www.dx.doi.org/10.5935/1415-2762.20190046

Organização Pan-Americana de Saúde. (2021). Transtornos mentais. https://www.paho.org/pt/topicos/transtornos-mentais

Paula, R. C. C., Rodrigues, M. A., \& Santana, R. F. (2018). Dimensionamento de pessoal de enfermagem nas instituições de longa permanência para idosos. Enfermagem em Foco, 9(1), 25-30. https://doi.org/10.21675/2357-707X.2018.v9.n1.1813

Pereira, L. P., Duarte, M. L. C., \& Eslabão, A. D. (2019). O cuidado à pessoa com comorbidade psiquiátrica em emergência geral: visão dos enfermeiros. Revista Gaúcha de Enfermagem, 40, e20180076. https://doi.org/10.1590/1983-1447.2019.20180076

Quevedo, J. (Org.). (2020). Emergências psiquiátricas (4a ed.). Artmed.

Sadock, B. J., Sadock, V. A., \& Ruiz, P. (2017). Compêndio de Psiquiatria: Ciência do Comportamento e Psiquiatria Clínica (11a ed.). Porto Alegre: Artmed. Santos, C. S., Bessa, T. A., \& Xavier, A. J. (2020). Fatores associados à demência em idosos. Ciência \& Saúde Coletiva, 25(2), 603-611. https://doi.org/10.1590/1413-81232020252.02042018.

Silva, P. O., Aguiar, B. M., Vieira, M. A., Costa, F. M., \& Carneiro, J. A. (2019). Prevalência de sintomas depressivos e seus fatores associados em idosos atendidos por um centro de referência. Revista Brasileira de Geriatria e Gerontologia, 22(5), e190088. Retrieved from https://doi.org/10.1590/198122562019022.190088 
Research, Society and Development, v. 10, n. 3, e16610313122, 2021

(CC BY 4.0) | ISSN 2525-3409 | DOI: http://dx.doi.org/10.33448/rsd-v10i3.13122

Silva, T. C. M. F., \& Marcolan, J. F. (2018). Preconceito aos indivíduos com transtorno mental como agravo do sofrimento. Revista de Enfermagem UFPE On Line, 12(8), 2089-2098. Retrieved from https://doi.org/10.5205/1981-8963-v12i8a234776p2089-2098-2018 